Document downloaded from:

http://hdl.handle.net/10251/51953

This paper must be cited as:

Oscar Carranza Castillo; Gabriel Garcerá; Figueres Amorós, E.; Luis Gerardo González Morales (2013). Low power wind energy conversion system based on variable speed permanent magnet synchronous generators. Wind Energy. 1-17. doi:10.1002/we.1598.

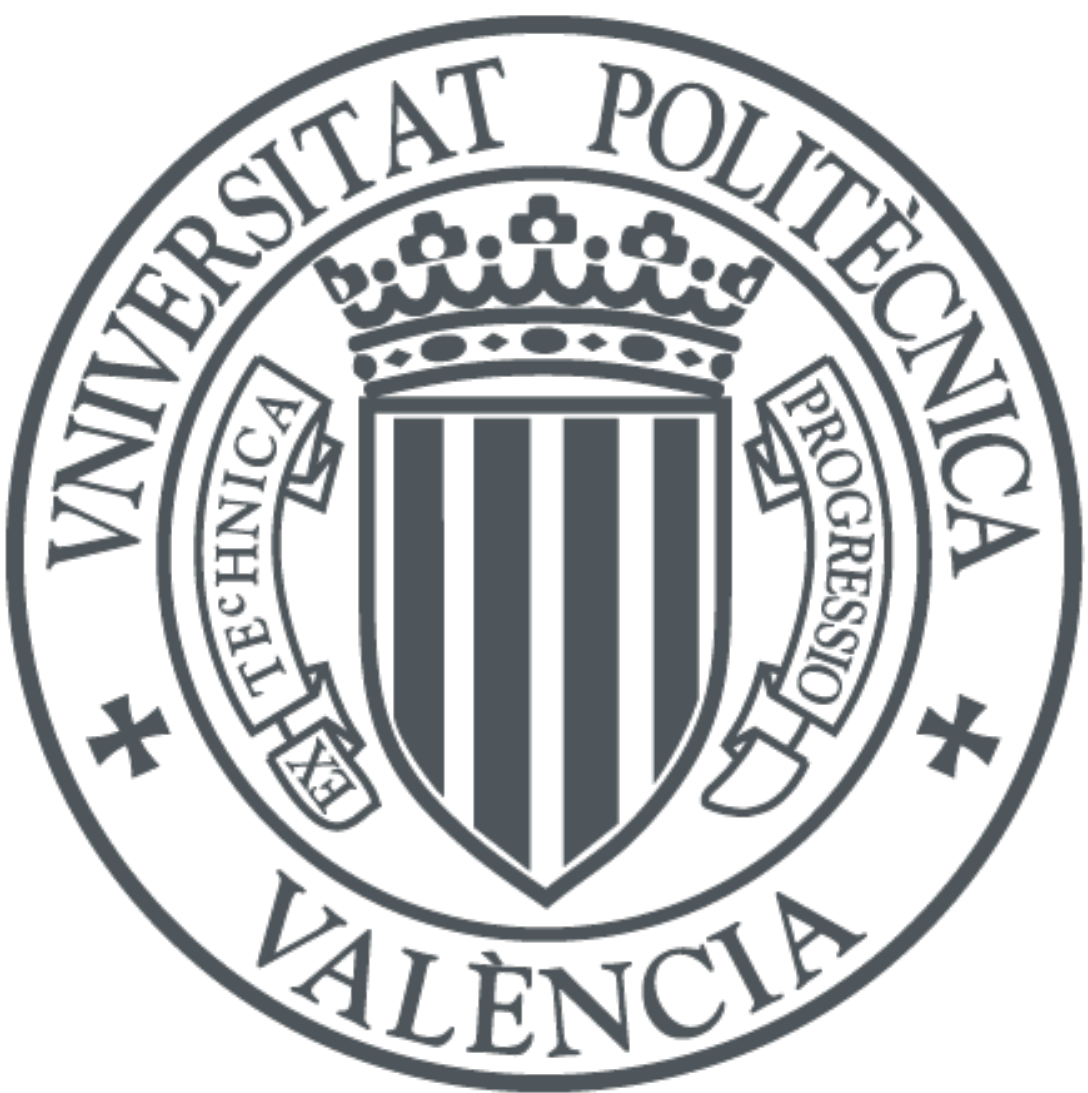

The final publication is available at

http://dx.doi.org/10.1002/we.1598

Copyright Wiley

Additional Information 


\title{
Low Power Wind Energy Conversion System based on Variable Speed Permanent Magnet Synchronous Generators
}

\author{
O. Carranza ${ }^{1}$, G. Garcerá ${ }^{2}$,E. Figueres ${ }^{2}$, L. G. González ${ }^{3}$ \\ ${ }^{1}$ Escuela Superior de Cómputo, Instituto Politécnico Nacional, \\ Av. Juan de Dios Batiz S/N, Col. Lindavista, Del. Gustavo A. Madero, \\ 07738, D.F., México, email ocarranzac@ipn.mx, \\ ${ }^{2}$ Grupo de Sistemas Electrónicos Industriales, Departamento de Ingeniería Electrónica, \\ Universidad Politécnica de Valencia, Camino de Vera S/N, 7F, 46020, \\ Valencia, Spain, http://www.gsei.upv.es, email: ggarcera@eln.upv.es, efiguere@eln.upv.es,, \\ ${ }^{3}$ Departamento de Ingeniería Electrónica y Comunicaciones, Universidad de los Andes \\ e-mail: Igerardo@ula.ve
}

\begin{abstract}
This paper presents a Low Power Wind Energy Conversion System based on a permanent magnet synchronous generator and a High Power Factor rectifier. To achieve a high power factor at the generator side, it is proposed a power processing scheme based on a diode rectifier and a boost DC-DC converter working in discontinuous conduction mode. The proposed generator control structure is based on three cascaded control loops that regulate the generator current, the turbine speed and the amount of power that it is extracted from the wind, respectively, following the turbine aerodynamics and the actual wind speed. The analysis and design of both the current and the speed loop have been carried out taking into consideration the electrical and mechanical characteristics of the wind energy conversion system, as well as the turbine aerodynamics. The power loop is not a linear one, but a Maximum Power Point Tracking algorithm, based on the Perturb and Observe technique, from which it is obtained the reference signal for the speed loop. Finally, to avoid the need of mechanical sensors, a linear Kalman Filter has been chosen to estimate the generator speed. Simulation and experimental results on a $2 \mathrm{~kW}$ prototype are shown to validate the concept.
\end{abstract}

\section{INTRODUCTION}

At the present time, wind energy is gaining a great acceptance among all renewable energies [1]-[2], but not all places are capable of taking full advantage of it. Several statistical methods have been developed to calculate the average wind speed, the wind power density and its capacity factor for a specific geographical area [3]-[4]. A Wind energy conversion system (WECS) is composed by a wind turbine, which includes the electrical generator and a power electronic converter. The power generation in WECS has a wide range, from a few $\mathrm{kW}$ to GW. In small power WECS ranging from $1 \mathrm{~kW}$ to $50 \mathrm{~kW}$ it is preferred the use of Permanent Magnet Synchronous Generators (PMSG) operating at a variable speed. In that case, the power electronic converter is usually composed by an AC/DC converter feeding a DC/AC converter (grid connection inverter). This paper is focused on the AC/DC converter, which is commonly implemented by means of two different topologies [5]. The first one is based on a non-controlled rectifier [6] that feeds a DC/DC converter, whose main drawbacks are a high $\mathrm{THD}_{\mathrm{i}}$ value of the generator currents and a poor Power Factor (PF). Typical values of that topology are: THDi $\approx X X \%$ and PF $\approx X X$. NOTA: Sacar los valores de la referencia [6] a potencias cercanas a la nominal, por ejemplo. Obviamente deben salir notablemente peores que los del back-to-back que se citan a continuación. As a result, the mechanical stress of the wind turbine is high and the efficiency is reduced. The second topology is based on a back-to-back converter, which improves both the $\mathrm{THD}_{\mathrm{i}}$ and the $\mathrm{PF}$, resulting in a better efficiency and a lower stress. Typical values of that topology are: THDi $\approx 3 \%$ and PF $\approx 0.98$. Those values do not justify the extra cost of using six IGBTs with their gate drive circuits in low power WECS. Summing up, the back-toback converter is a good choice for medium and high power WECS, whereas the boost rectifier with a single active switch is preferred for low power, low cost applications.

This paper proposes the use of a Three-Phase Boost Rectifier operating in Discontinuous Conduction Mode (DCM), because it is useful to reduce the $\mathrm{THD}_{\mathrm{i}}$ and to increase the PF of the wind power generator, with a similar cost to that of conventional low power topologies. DCM has been proposed in [7]-[10] to reduce the $\mathrm{THD}_{\mathrm{i}}$ in switch-mode power supplies (SMPS). However, its application to WECS has not been explored. A contribution of this paper regarding [7]-[10] is that the operation frequency of the boost rectifier is variable following the generator speed, whereas the grid frequency in the case of an SMPS is practically fixed at $50 \mathrm{~Hz}$ or $60 \mathrm{~Hz}$. The disadvantage of working in DCM is that the peak currents through the rectifier components are higher than in continuous conduction mode, a fact that has to be considered during the selection process and thermal design of these components. 
Besides, an input LC filter between the wind generator and the rectifier must be added in order to achieve DCM operation at a reasonable switching frequency, so that the stability of the whole system may be compromised if the control loops are not carefully studied and designed.

In general, torque control structures [11] or speed control structures [12] can be used for WECS based on PMSGs. In this work a current control loop regulates the PMSG torque, which directly depends on the generator currents and, thus, on the dc output current of the rectifier. An additional speed loop is implemented that provides the current reference to the current loop. The speed loop includes the behavior of the wind turbine considering both mechanical and electrical characteristics. In order to eliminate the need of mechanical speed sensors placed on the shafts of the PMSG, it is proposed the use of a speed estimator based on a linear Kalman Filter [13]. A Maximum Power Point Tracking (MPPT) algorithm [14]-[15] has been implemented by means of the Perturb and Observe (P\&O) technique. The analysis and design of the grid connection inverter stage is beyond the scope of the present study.

In this paper both simulation and experimental results are shown to validate the proposed control structure for the wind energy conversion system.

\section{MODELING OF THE WIND TURBINE}

Fig. 1 shows the scheme of the proposed WECS, whereas Table I shows the values of its most relevant parameters. In Fig. 1 $L_{a}=L_{b}=L_{c}$ are the Boost inductances associated to each phase, $R_{L a}=R_{L b}=R_{L c}$ are the parasitic series resistances associated to the Boost inductors in each phase, and $C_{f 1}=C_{f 2}=C_{f 3}$ are the input filter capacitors.

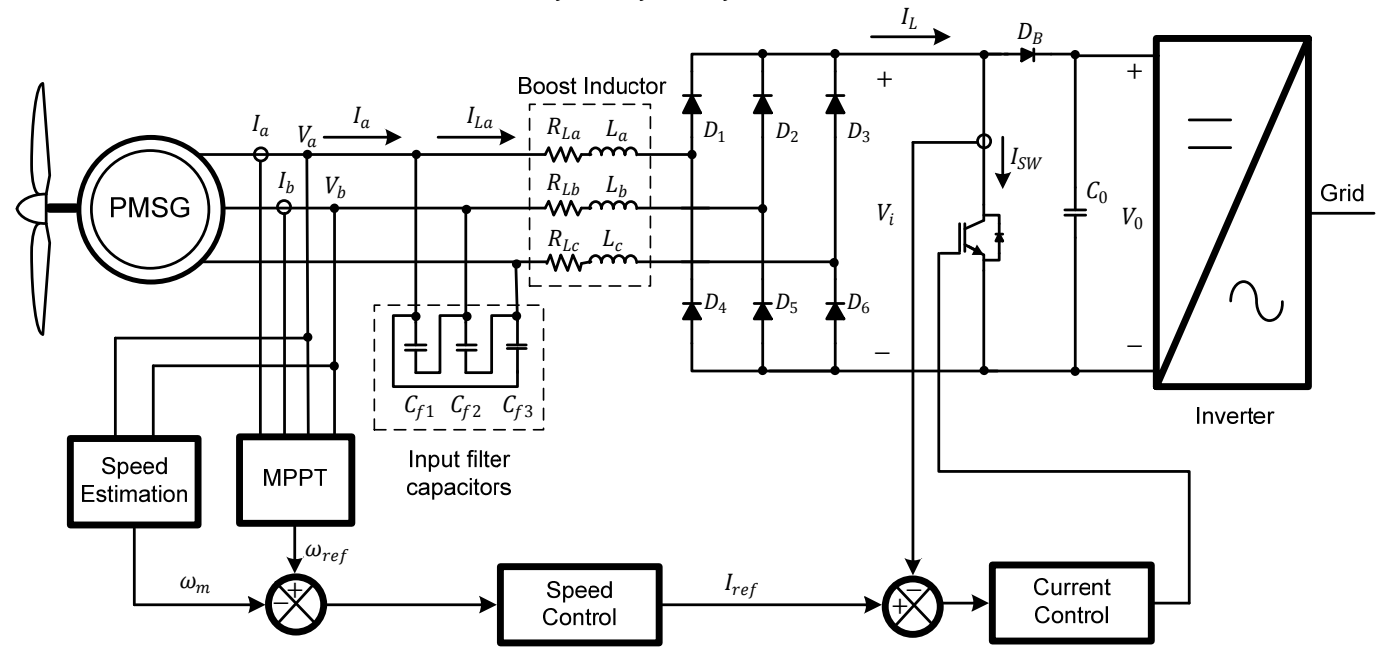

Fig. 1. Scheme of the proposed WECS.

TABLE I. CHARACTERISTICS IN THE PROPOSED WECS.

\begin{tabular}{lc}
\hline \multicolumn{1}{c}{ Characteristics } & Values \\
\hline Output power of the generator $\left(P_{o}\right)$ & $2 \mathrm{~kW}$ \\
Output voltage range of the generator $\left(V_{a b}=V_{b c}=V_{c a}\right)$ & $104-416 V_{r m s}$ \\
Constant of the electromotive force $\left(K_{f e m}\right)$ & $0.9022 V_{\text {peak }} / \mathrm{rad} / \mathrm{s}$ \\
Number of poles $\left(n_{p}\right)$ & 12 \\
Speed range of the generator $\left(n_{m}\right)$ & $150-600 \mathrm{rpm}$ \\
Angular mechanical frequency range of the generator $\left(\omega_{m}=\pi \cdot n_{m} / 30\right)$. & $15.7-62.83 \mathrm{rad} / \mathrm{s}$ \\
Angular electrical frequency range of the generator $\left(\omega_{e}=\omega_{m} \cdot n_{p} / 2\right)$ & $94.2-376.98 \mathrm{rad} / \mathrm{s}$ \\
Inductance of one phase of the generator $\left(L_{g a}=L_{g b}=L_{g c}\right)$ & $25 \mathrm{mH}$ \\
Resistance of one phase of the generator $\left(R_{L g a}=R_{L g b}=R_{L g c}\right)$ & $5 \Omega$ \\
Wind turbine coefficients & $\mathrm{d}=0.0605, \mathrm{e}=0.0104, \mathrm{f}=0.0006$ \\
Wind turbine ratio $(r)$ & $1.525 \mathrm{~m}$ \\
Inertia Coefficient of the system $(\mathrm{J})$ & $0.5 \mathrm{~kg} \mathrm{~m} / \mathrm{s}$ \\
Density of wind $(\rho)$ & $1.08 \mathrm{~kg} / \mathrm{m} 3$ \\
Boost converter Switching frequency $\left(f_{s w}\right)$ & $5 \mathrm{kHz}$ \\
Boost inductance associated to each phase $\left(\mathrm{L}_{\mathrm{a}}=\mathrm{L}_{\mathrm{b}}=\mathrm{L}_{\mathrm{c}}\right)$ & $0.108, \mathrm{c}=0.146$ \\
Parasitic series resistance associated to the Boost inductor in each phase $\left(R_{L a}=R_{L b}=R_{L c}\right)$ & $375 \mu \mathrm{H}$ \\
Input Filter Capacitors $\left(C_{f 1}=C_{f 2}=C_{f 3}\right)$ & $37.5 \mathrm{~m} \Omega$. \\
\hline
\end{tabular}




\begin{tabular}{lc} 
DC link Capacitance $\left(C_{0}\right)$ & $2 \mathrm{mF}$ \\
DC link voltage $\left(V_{0}\right)$ & $650 \mathrm{~V}$ \\
Boost IGBT switch & IRG4PF50WDPBF \\
Boost Diode $\left(D_{B}\right)$ & HFA16PB120PBF \\
Bridge Rectifier & $26 \mathrm{MT} 120$ \\
DSP Sampling time $\left(T_{s}\right)$ & $10 \mu \mathrm{s}$ \\
\hline
\end{tabular}

\section{A. Wind Turbine Model}

The mechanical behavior of the wind turbine follows (1)

$$
J \frac{d \omega_{m}}{d t}+B \omega_{m}=T_{m}-T_{e}
$$

where $J$ is inertia coefficient, $B$ is the friction coefficient, $\omega_{m}$ is the turbine rotational speed, $T_{m}$ is the turbine mechanical torque and $T_{e}$ is the electrical torque applied to the PMSG rotor.

The mechanical power generated by the wind turbine $\left(P_{m}\right)$ and $T_{m}$ are expressed by equations (2) and (3), respectively.

$$
\begin{aligned}
& P_{m}=\frac{1}{2} \rho \pi r^{2} C_{p}(\lambda) V_{\omega}^{3} \\
& T_{m}=\frac{1}{2} \rho \pi r^{3} C_{t}(\lambda) V_{\omega}^{2}
\end{aligned}
$$

where $\rho$ is the density of the air, $r$ is the wind turbine rotor radius, $V_{\omega}$ is the wind speed, $C_{p}(\lambda)$ is the power coefficient, $C_{t}(\lambda)$ is the torque coefficient. Both coefficients depend on the tip-speed-ratio $(\lambda)$, expressed by (4).

$$
\lambda=\frac{r \omega_{m}}{V_{\omega}}
$$

$C_{p}(\lambda)$ is expressed by (5) and $C_{t}(\lambda)$ is expressed by (6). Fig. 2 shows both $C_{p}(\lambda)$ and $C_{t}(\lambda)$ characteristics as a function of the tip-speed ratio.

$$
\begin{gathered}
C_{p}(\lambda)=a+b \lambda+c \lambda^{2}+d \lambda^{3}+e \lambda^{4}+f \lambda^{5} \\
C_{t}(\lambda)=\frac{C_{p}(\lambda)}{\lambda}
\end{gathered}
$$

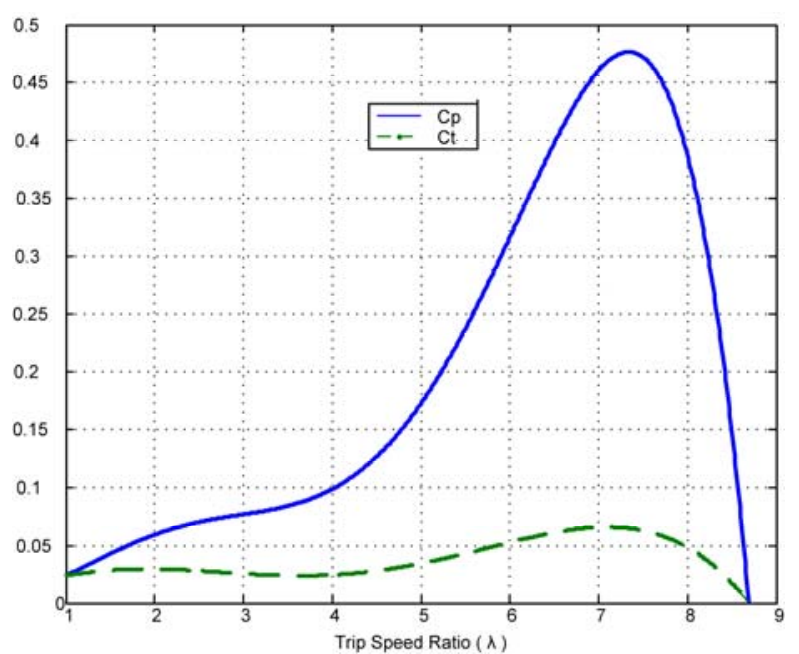

Fig. 2. Power and torque coefficients. 


\section{B. Permanent Magnet Synchronous Generator Model}

The equivalent circuit of the permanent magnet synchronous generator [17] is shown in Fig. 3. $\mathrm{L}_{\mathrm{ga}}=\mathrm{L}_{\mathrm{gb}}=\mathrm{L}_{\mathrm{gc}}$ are the inductances of one phase, $\mathrm{R}_{\mathrm{Lga}}=\mathrm{R}_{\mathrm{Lgb}}=\mathrm{R}_{\mathrm{Lgc}}$ are the series resistance of one phase, $\mathrm{V}_{\mathrm{a}}, \mathrm{V}_{\mathrm{b}}$ and $\mathrm{V}_{\mathrm{c}}$ are the generator instantaneous output voltages, and $\mathrm{e}_{\mathrm{a}}, \mathrm{e}_{\mathrm{b}}$ and $\mathrm{e}_{\mathrm{c}}$ are the electromotive forces, which are expressed by (7).

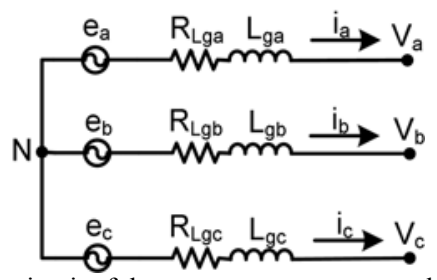

Fig. 3. Equivalent circuit of the permanent magnet synchronous generator.

$$
\begin{gathered}
e_{a}=K_{e m f} \omega_{e} \sin \left(\omega_{e} t\right) \\
e_{b}=K_{e m f} \omega_{e} \sin \left(\omega_{e} t-\frac{2 \pi}{3}\right) \\
e_{c}=K_{e m f} \omega_{e} \sin \left(\omega_{e} t+\frac{2 \pi}{3}\right)
\end{gathered}
$$

In (7) $K_{e m f}$ stands for the electromotive force constant, whereas $\omega_{\mathrm{e}}$ is the electrical angular frequency of the PMSG.

The electric equations of the PMSG are described by (8).

$$
\left[\begin{array}{l}
V_{a} \\
V_{b} \\
V_{c}
\end{array}\right]=-R_{L g a}\left[\begin{array}{l}
i_{a} \\
i_{b} \\
i_{c}
\end{array}\right]-L_{g a} \frac{d}{d t}\left[\begin{array}{l}
i_{a} \\
i_{b} \\
i_{c}
\end{array}\right]+\left[\begin{array}{l}
e_{a} \\
e_{b} \\
e_{c}
\end{array}\right]
$$

Analyzing the behavior of the PMSG, it is obtained that the electromotive torque $\left(T_{e}\right)$ is determined by (9)

$$
T_{e}=\frac{3 K_{e m f} n_{p} I_{g}}{2 \sqrt{2}}
$$

where $n_{p}$ is the number of the machine poles and $I_{g}$ is the rms value of the generator phase current.

\section{ThreE -Phase Boost ReCTIFIER With PCC In DisContinUOUS CONDUCTION MODE}

The Boost Rectifier operating in DCM achieves a Total Harmonic Distortion $\left(T H D_{i}\right)$ of the generator currents [18], much lower than that achieved by the same topology operating in Continuous Conduction Mode (CCM), improving the power factor of the generator [19]. In [18], a Three-Phase Boost Rectifier operating in Discontinuous Conduction Mode (DCM) with Peak Current Mode Control (PCC) was presented and analyzed in detail. In the current paper only the most relevant issues are shown to perform the analysis of the whole system.

The current loop of the DCM boost rectifier under study starts from the information of the bridge rectifier DC output current, $i_{L}$. This current waveform operates in DCM. It is observed from Fig. 1 that the current through the boost active switch, $i_{S W}$, is sensed instead for performing PCC. This current agrees with $i_{L}$ when this switch is in its 'on' state, so that isw is the same state variable. Note that $i_{L}$ is the equivalent boost inductor current or boost input current. In the proposed topology the boost inductances are placed at the AC side, before the diode bridge rectifier, instead of standing at the DC side, just after the rectifier bridge.

$G_{i d}(s)=\hat{\imath}_{L}(s) / \hat{d}(s)$ is the transfer function from the duty cycle to the diode rectifier output current (or the equivalent boost inductor current), expressed by (10).

$$
G_{i d}(s)=\frac{\hat{l}_{L}(s)}{\hat{d}(s)}=\frac{-\left(s^{2} C_{i} L_{g}+s C_{i} R_{g}+1\right)\left(K_{i}+K_{o}\right)}{s^{3} B_{3}+s^{2} B_{2}+s B_{1}+B_{0}}
$$




$$
\begin{gathered}
B_{3}=C_{i} L_{g} L\left(g_{i}+g_{o}+g_{f}\right) \\
B_{2}=C_{i}\left[L_{g}+\left(g_{i}+g_{o}+g_{f}\right)\left(L R_{L_{g}}+L_{g} R_{L}\right)\right] \\
B_{1}=\left[C_{i} R_{L_{g}}+\left(g_{i}+g_{o}+g_{f}\right)\left(L_{g}+L+C_{i} R_{L} R_{L_{g}}\right)\right] \\
B_{0}=\left(g_{i}+g_{o}+g_{f}\right)\left(R_{L_{g}}+R_{L}\right)+1
\end{gathered}
$$

where the values of the parameters of the PWM switch small-signal model in DCM [20] are shown in (11).

$$
\begin{gathered}
g_{i}=\frac{D^{2}}{2 L f_{s}} \quad g_{o}=\frac{2 L P_{o}^{2} f_{s}}{D^{2} V_{i}^{2} V_{o}^{2}} \quad g_{f}=\frac{2 P_{o}}{V_{i} V_{o}} \\
K_{i}=-\frac{D V_{i}}{L f_{s}} \quad K_{o}=-\frac{2 P_{o}}{D V_{o}}
\end{gathered}
$$

In (10) and (11) it is considered: $L_{g}=2 L_{g a}, R_{L g}=2 R_{L g a}, \quad L=2 L_{a}, R_{L}=2 R_{L a}$ and $C_{i}=3 C_{f 1} / 2 . \mathrm{D}$ is the duty cycle of the boost active switch. $V_{i}$ is the average value of the Boost DC-DC converter input voltage, as it is shown in Fig. 1. The boost rectifier output voltage, $V_{o}$, is regulated by the grid connected inverter to a constant value of $650 \mathrm{~V}$. $P_{o}$ is the output power at the operating point, which is limited to the maximum value allowed by the PMSG.

Fig. 4 shows the block diagram of the current loop with PCC [10]. The reference for the current loop, $I_{r e f}$, is provided by the controller of the speed control loop.

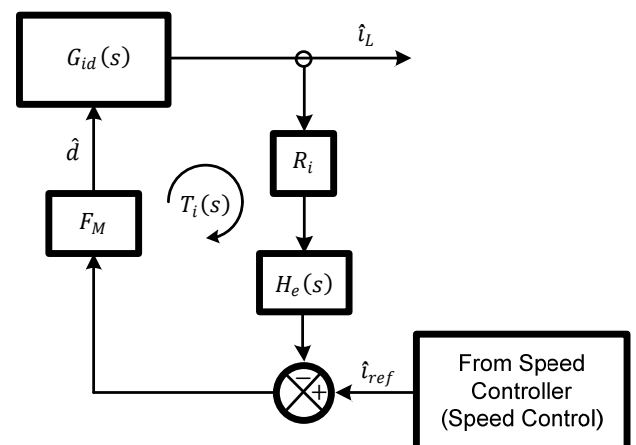

Fig. 4. Peak Current-Mode Control Loop.

The loop gain of the current loop, $T_{i}(s)$, is expressed by (12). $R_{i}=0.015 \Omega$ is the current sense gain, $F_{M}$ is the PWM modulator gain, and $H_{e}(s)$ is the sampling gain [21], typical in peak current mode control.

$$
T_{i}(s)=G_{i d}(s) H_{e}(s) R_{i} F_{M}
$$

The sampling gain $H_{e}(s)$ is expressed by ¡Error! No se encuentra el origen de la referencia.

$$
H_{e}(s)=1+\frac{s}{\omega_{z} Q_{z}}+\frac{s^{2}}{\omega_{z}^{2}}
$$

where

$$
\begin{gathered}
\omega_{z}=\frac{\pi}{T_{s}}=\frac{\pi}{200 \mu \mathrm{s}}=15707.963 \frac{\mathrm{rad}}{\mathrm{s}} \\
Q_{z}=-\frac{2}{\pi}=-0.6366
\end{gathered}
$$

In order to guarantee the stability of the current loop, the PWM modulator gain, $\mathrm{F}_{\mathrm{M}}$, expressed by (14), should be adjusted properly. 


$$
F_{M}=\frac{1}{\left(S_{n}+S_{e}\right) T_{s}}
$$

In (14) $S_{n}$ is the on-time slope of the current sense waveform, $S_{e}$ is the slope of the stabilization ramp, $S e=22.503 \mathrm{~V} /$ $m s$. The value of $S_{n}$ is obtained from (15).

$$
S_{n} \approx \frac{V_{i}}{L} R_{i}
$$

As the PMSG torque depends on the generator currents, it is important to know the relationship between the generator current and the equivalent boost inductor current, following (16).

$$
\frac{\hat{\imath}_{g}(s)}{\hat{\imath}_{L}(s)}=\frac{1}{s^{2} C_{i} L_{g}+s C_{i} R_{L g}+1}
$$

\section{SPEED CONTROL}

\section{A. Speed Control Loop}

To design the speed control loop, it is necessary to perform a small-signal analysis around the operating point. Starting from equation (1), it is obtained (14). The following nomenclature is adopted: any dynamic variable $x$ is represented as: $=X+\hat{x}$, where $X$ is the operation point value and $\hat{x}$ is the small-signal term. The small-signal expression of the generator speed follows (17), as it can be derived from (1) and neglecting the friction coefficient.

$$
\widehat{\omega}_{m}=\frac{1}{J \cdot s}\left(\widehat{T}_{m}-\widehat{T}_{e}\right)
$$

$T_{m}$ strongly depends on both the speed of the PMSG, $\omega_{m}$, and the wind speed, $v_{\omega}$ as it is shown in (3)-(6). A linear model of $T_{m}$ may be obtained by applying a first order Taylor series around the operation point. Note that one of the inputs of the resulting linear model is the wind speed, which is considered as an external disturbance, and the other one is an inherent feedback of the generator speed.

$$
\widehat{T}_{m}=\left.\widehat{\omega}_{m} \frac{\partial\left[T_{m}\left(\omega_{m}, v_{\omega}\right)\right]}{\partial \omega_{m}}\right|_{\substack{\omega_{m}=W_{m} \\ v_{\omega}=V_{\omega}}}+\left.\hat{v}_{\omega} \frac{\partial\left[T_{m}\left(\omega_{m}, v_{\omega}\right)\right]}{\partial v_{\omega}}\right|_{\substack{\omega_{m}=W_{m} \\ v_{\omega}=V_{\omega}}}
$$

As the wind speed is an external disturbance, $\hat{v}_{\omega}=0$ is considered to analyze the stability of the speed control loop. The small-signal term of $T_{m}$ is expressed by 19 ).

$$
\left.\widehat{T}_{m}\right|_{\hat{v}_{\omega}=0}=\frac{1}{2} \rho \pi r^{3} V_{\omega}^{2}\left(-\frac{a V_{\omega}}{r W_{m}^{2}}+\frac{c r}{V_{\omega}}+\frac{2 d r^{2} W_{m}}{V_{\omega}^{2}}+\frac{3 e r^{3} W_{m}^{2}}{V_{\omega}^{3}}+\frac{4 f r^{4} W_{m}^{3}}{V_{\omega}^{4}}\right) \widehat{\omega}_{m}
$$

The small-signal expression of the electrical torque may be obtained from (9), resulting in (20).

$$
\widehat{T}_{e}=\frac{3 K_{e m f} \hat{\imath}_{g}}{\sqrt{2}}
$$

The structure of the speed loop is shown in Fig. 5. Considering that there are not variations in wind speed, $\hat{v}_{\omega}=0$, the PMSG speed is expressed by (21), as it can be derived from (17).

$$
\widehat{\omega}_{m}=\frac{1}{J \cdot s}\left(\left.\widehat{T}_{m}\right|_{\hat{v}_{\omega}=0}-\widehat{T}_{e}\right)
$$




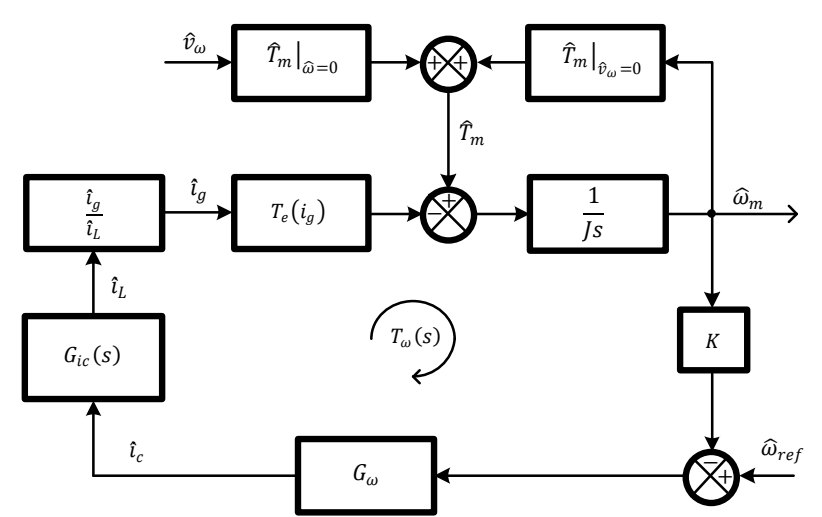

Fig. 5. Block diagram of the Speed Control Loop.

From 19)-(21) it is possible to deduce the relationship between the PMSG speed and its output current, following (22).

$$
\begin{gathered}
\left.\frac{\widehat{\omega}_{m}(s)}{\hat{l}_{g}(s)}\right|_{\widehat{v}_{\omega}=0}=-\frac{3 K_{f e m}}{\sqrt{2}\left[J \cdot s-\frac{1}{2} \rho \pi r^{3} V_{\omega}^{2} a_{1}\right]} \\
a_{1}=\left(-\frac{a V_{\omega}}{r W_{m}^{2}}+\frac{c r}{V_{\omega}}+\frac{2 d r^{2} W_{m}}{V_{\omega}^{2}}+\frac{3 e r^{3} W_{m}^{2}}{V_{\omega}^{3}}+\frac{4 f r^{4} W_{m}^{3}}{V_{\omega}^{4}}\right)
\end{gathered}
$$

The loop gain of the speed loop, $T_{\omega}(s)$, is determined by (23).

$$
T_{\omega}(s)=G_{\omega c}(s) \cdot K \cdot G_{\omega}(s)
$$

where $K=1$ is the speed sensing gain, $G_{\omega}(s)$ is the transfer function of a simple proportional-integral controller, and $G_{\omega c}(s)$ is the transfer function from the reference current to the PMSG speed, which it is expressed by (24).

$$
G_{\omega c}(s)=\frac{\widehat{\omega}_{m}(s)}{\hat{\imath}_{\text {ref }}(s)}=\frac{\widehat{\omega}_{m}(s)}{\hat{l}_{g}(s)} \cdot \frac{\hat{l}_{g}(s)}{\hat{l}_{L}(s)} \cdot \frac{\hat{\imath}_{L}(s)}{\hat{\imath}_{r e f}(s)}
$$

The chosen gains for the PI speed controller, $G_{\omega}$, are: $K_{p}=-0.05777$ and $K_{i}=-0.0187752 \mathrm{rad} / \mathrm{s}$. The closed loop transfer function from the reference speed to the PMSG speed is given by (25). Fig. 6 shows the Bode plots of $T_{\omega}(s)$ with the chosen controller. The reference for the speed loop is provided by the MPPT algorithm.

$$
G_{\omega r}(s)=\frac{\widehat{\omega}_{m}(s)}{\widehat{\omega}_{r e f}(s)}=\frac{G_{\omega c}(s) \cdot G_{\omega}(s)}{1+T_{\omega}(s)}
$$




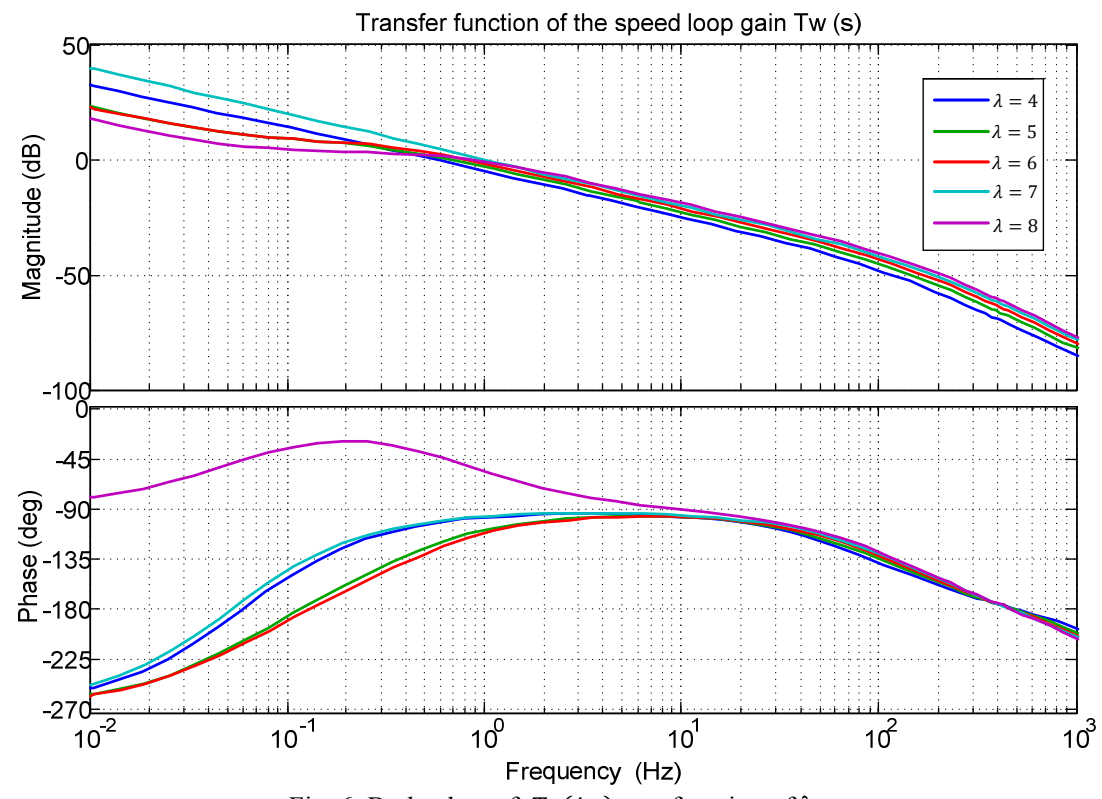

Fig. 6. Bode plots of $T_{\omega}(j \omega)$ as a function of $\lambda$.

\section{B. Speed Estimation using Linear Kalman Filter}

To obtain the feedback signal for the speed control loop, it is possible to mount speed sensors on the shafts of the PMSG (resolvers, encoders or Hall-effect sensors). However, the use of those sensors increases the complexity, weight and cost of PMSG.

As both the voltages and frequency of the generator depend on its speed, the PMSG speed can be estimated starting from the measurement of the electrical quantities, eliminating the need for mechanical sensors. The problem is that the measured signals contain low frequency harmonics of the fundamental frequency of the generator, as well as switching frequency components due to the boost rectifier. Furthermore, the fundamental and its low frequency harmonics have different values depending on the generator speed. These issues have been studied in [22], concluding that the use of a Linear Kalman Filter (LKF) is a good compromise among dynamical response, static performance and complexity of implementation. In this case sensors are used to measure the generator output voltages, from which the LKF speed estimation is applied. The main equations of the LKF estimator used in this work are expressed by (26). The meaning of each variable of (26) in explained in [22].

$$
\begin{gathered}
\varepsilon(k)=V_{\beta}(k) \cos \theta(k)-V_{\alpha}(k) \sin \theta(k) \\
\theta(k+1)=\theta(k)+T_{s} \omega_{e}(k)+K_{s 1} \varepsilon(k) \\
\omega_{e}(k+1)=\omega_{e}(k)+\dot{\rho}(k)+K_{s 2} \varepsilon(k) \\
\dot{\rho}(k+1)=\dot{\rho}(k)+K_{s 3} \varepsilon(k)
\end{gathered}
$$

The chosen values of the LKF parameters are: $\delta=5 \times 10^{6}, K_{s 1}=0.0032896, K_{s 2}=0.54221$ and $K_{s 3}=0.00044647$. It is worth pointing out that the LKF gains are independent of the PMSG parameters and could be used with a different generator. Another advantage of the LKF speed estimator is that the only measurement needed is that of the output voltages of the PMSG, reducing the cost of the sensors in the system.

\section{MAXIMUM POWER POINT TRACKING}

To calculate the proper values for the parameters of the Maximum Power Point Tracking algorithm and assure the system stability, it is useful to know the response of the generated power to variations of the PMSG speed [23]. The power generated by the PMSG is given by (27)

$$
P_{\text {out }}=T_{e} \omega_{m}-I_{g}^{2} R_{L g a}
$$

Applying (9) to (27) and performing the linearization by first order Taylor series around the operation point, it is obtained:

$$
\hat{P}_{\text {out }}=\left.\widehat{\omega}_{m} \frac{\partial\left[P_{\text {out }}\left(\omega_{m}, i_{g}\right)\right]}{\partial \omega_{m}}\right|_{\begin{array}{c}
\omega_{m}=W_{m} \\
i_{g}=I_{g}
\end{array}}+\left.\hat{\imath}_{g} \frac{\partial\left[P_{\text {out }}\left(\omega_{m}, i_{g}\right)\right]}{\partial i_{g}}\right|_{\begin{array}{c}
\omega_{m}=W_{m} \\
i_{g}=I_{g}
\end{array}}
$$




$$
\hat{P}_{\text {out }}=\widehat{\omega}_{m} \frac{3 K_{f e m} I_{g}}{\sqrt{2}}+\hat{\imath}_{g}\left(\frac{3 K_{f e m} W_{m}}{\sqrt{2}}-2 I_{g} R_{L g}\right)
$$

By assuming a constant wind speed $\left(\hat{v}_{\omega}=0\right)$, it may be substituted (22) in (29), obtaining the transfer function from the PMSG speed to its output power, following (30).

$$
\begin{gathered}
\left.\frac{\hat{P}_{\text {out }}(s)}{\widehat{\omega}_{m}(s)}\right|_{\hat{v}_{\omega}=0}=\frac{3 K_{f e m}}{\sqrt{2}} I_{g}-\frac{\sqrt{2}\left(\frac{3 K_{\text {fem }}}{\sqrt{2}} W_{m}-2 R_{L g L_{a}} I_{g}\right)\left[J \cdot s-\frac{1}{2} \rho \pi r^{3} a_{2}\right]}{3 K_{f e m}} \\
a_{2}=\frac{1}{2} \rho \pi r^{3} V_{\omega}^{2}\left(-\frac{a V_{\omega}}{r W_{m}^{2}}+\frac{c r}{V_{\omega}}+\frac{2 d r^{2} W_{m}}{V_{\omega}^{2}}+\frac{3 e r^{3} W_{m}^{2}}{V_{\omega}^{3}}+\frac{4 f r^{4} W_{m}^{3}}{V_{\omega}^{4}}\right)
\end{gathered}
$$

By multiplying (25) and (30), it is obtained the transfer function from the speed reference to the output power, $G_{P r}(s)$, as it is expressed by (31).

$$
G_{P r}(s)=\frac{\widehat{\omega}_{m}(s)}{\widehat{\omega}_{r e f}(s)} \cdot \frac{\hat{P}_{\text {out }}(s)}{\widehat{\omega}_{m}(s)}=\frac{\hat{P}_{\text {out }}(s)}{\widehat{\omega}_{\text {ref }}(s)}
$$

Fig. 7 shows the response of the PMSG power to a $1 \mathrm{rad} / \mathrm{s}$ step of the speed reference for several values of $\lambda$. The reference step happens at $t=0 \mathrm{~s}$, so that a non-minimum phase response can be observed. It is observed that the steady-state error decreases with $\lambda$, being minimized with $\lambda=7$.

The implemented MPPT algorithm is Perturb and Observe (P\&O), which is an iterative algorithm that can work in a wide range of wind speeds. The algorithm varies the value for the speed reference after evaluation of the measured power variation, taking into account the sign of the previous reference change. If power increases, the algorithm keeps the sign, otherwise, the sign changes. Obviously, a non-minimum phase response misleads a P\&O algorithm if the power measurement is performed before it has taken the right sign. The iteration time of the P\&O MPPT algorithm must be chosen longer than the settling times observed in Fig. 7. The proposed values for this work are: iteration time, $t_{\mathrm{s}}=4 \mathrm{~s}$, and amplitude of the speed reference steps of 1 $\mathrm{rad} / \mathrm{s}$.

\section{Simulation Results}

The performance of the proposed WECS has been evaluated by means of PSIM 7.0.5 software [24].

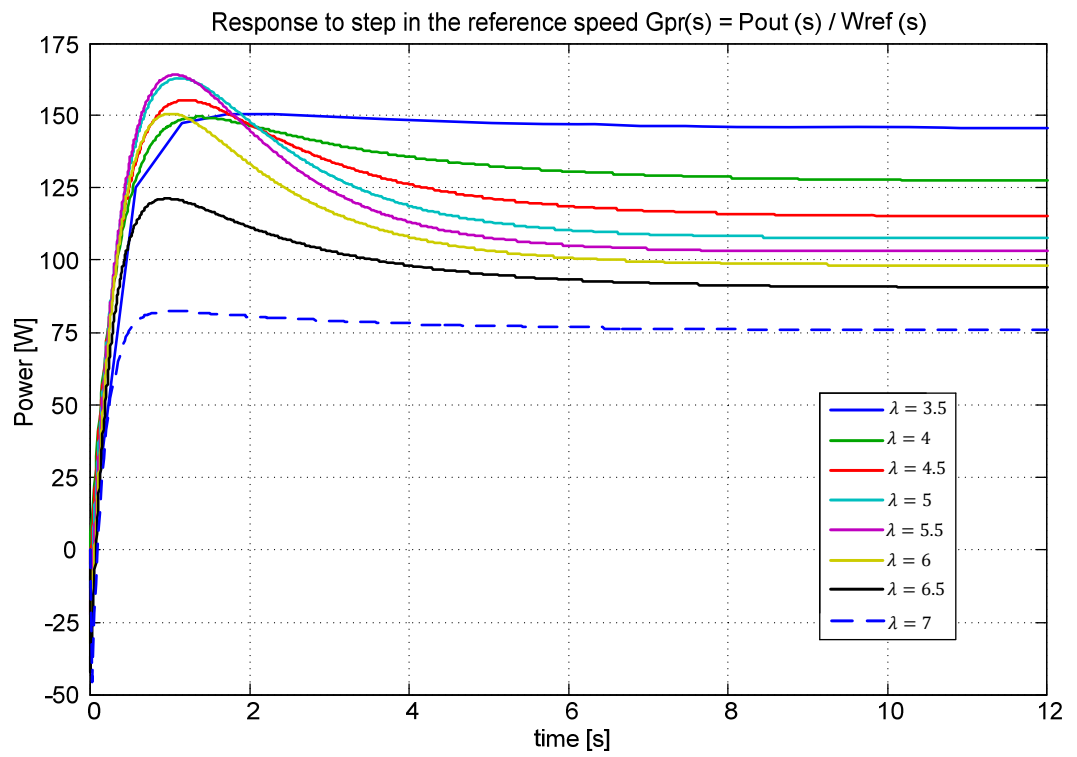

Fig. 7. Response of the PMSG power to steps of $1 \mathrm{rad} / \mathrm{s}$ in the speed reference as a function of $\lambda$.

Fig. 8 depicts the response of the generator speed LKF estimator to steps of the actual speed in the whole operation range. The steady-state error of the estimated speed is zero. The LKF estimator has a maximum ripple of $\pm 0.3 \mathrm{rpm}$ and a response time of $110 \mathrm{~ms}$. 

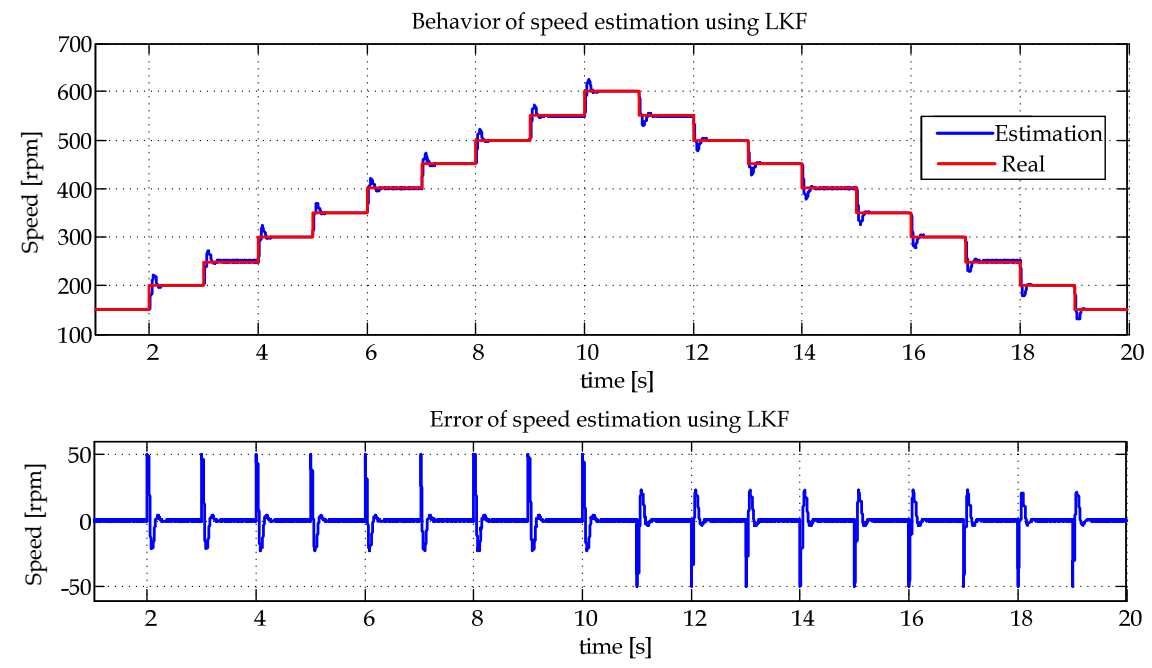

Fig. 8. The response of the LKF speed estimator to generator speed steps.

Fig. 9 shows the behavior of the speed loop to steps in the speed reference, $\Delta V_{\text {ref }}=50 \mathrm{rpm}$. The update time of the speed reference is $\Delta t=10 \mathrm{~s}$. It is observed that the speed loop properly follows the reference value. In this case the WECS operates at a constant wind speed of $10 \mathrm{~m} / \mathrm{s}$. Fig. 9 also shows the behavior of the electric torque and the PMSG output power.
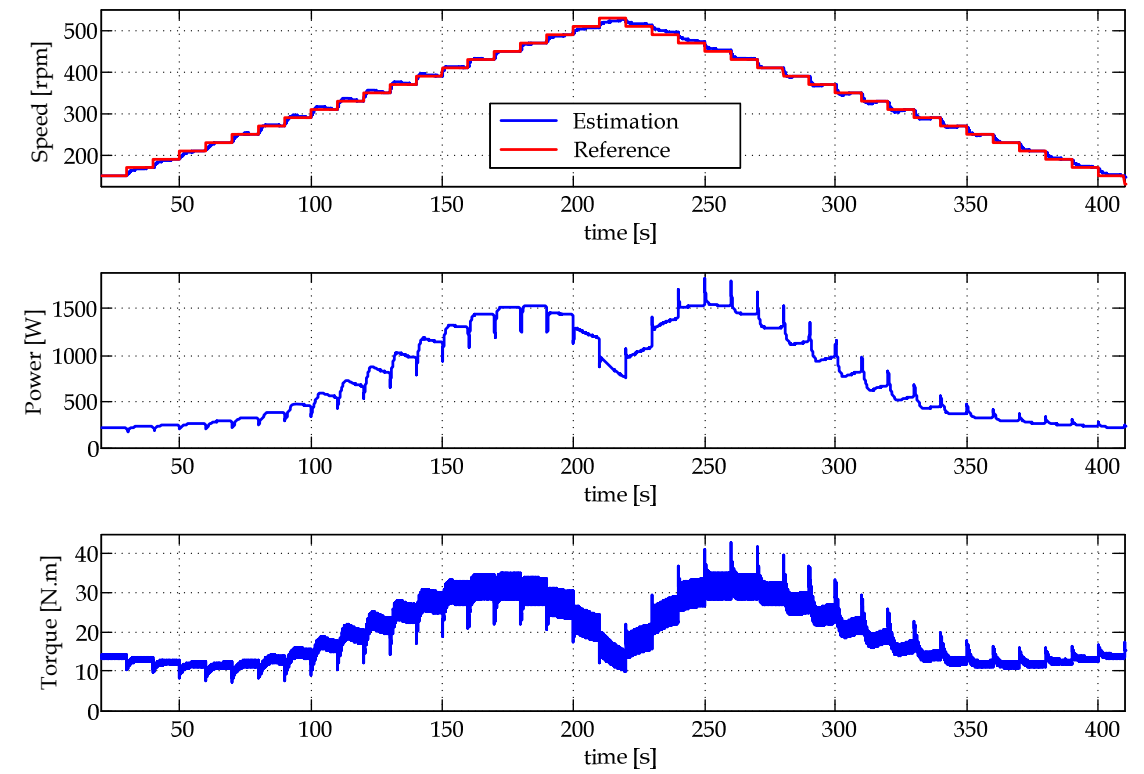

Fig. 9. Response of the speed loop to speed reference steps at a wind speed of $10 \mathrm{~m} / \mathrm{s}$. Top: generator speed estimation and its reference. Middle: Generator output power. Bottom: Electric torque.

Fig. 10 depicts the MPPT P\&O algorithm performance, running at an update frequency of the speed reference of $\mathrm{f}_{\mathrm{MPPT}}=1 / \Delta \mathrm{t}_{\mathrm{MPPT}}=0.1 \mathrm{~Hz}$, at a stepped variation of the wind speed, ranging from $6 \mathrm{~m} / \mathrm{s}$ to $10 \mathrm{~m} / \mathrm{s}$. It is observed that the MPPT is aiming to get the maximum value of the power coefficient $(0.47)$, so that the generated power is close to the maximum available one. The evolution of the generator speed using the LKF estimator is also shown. 

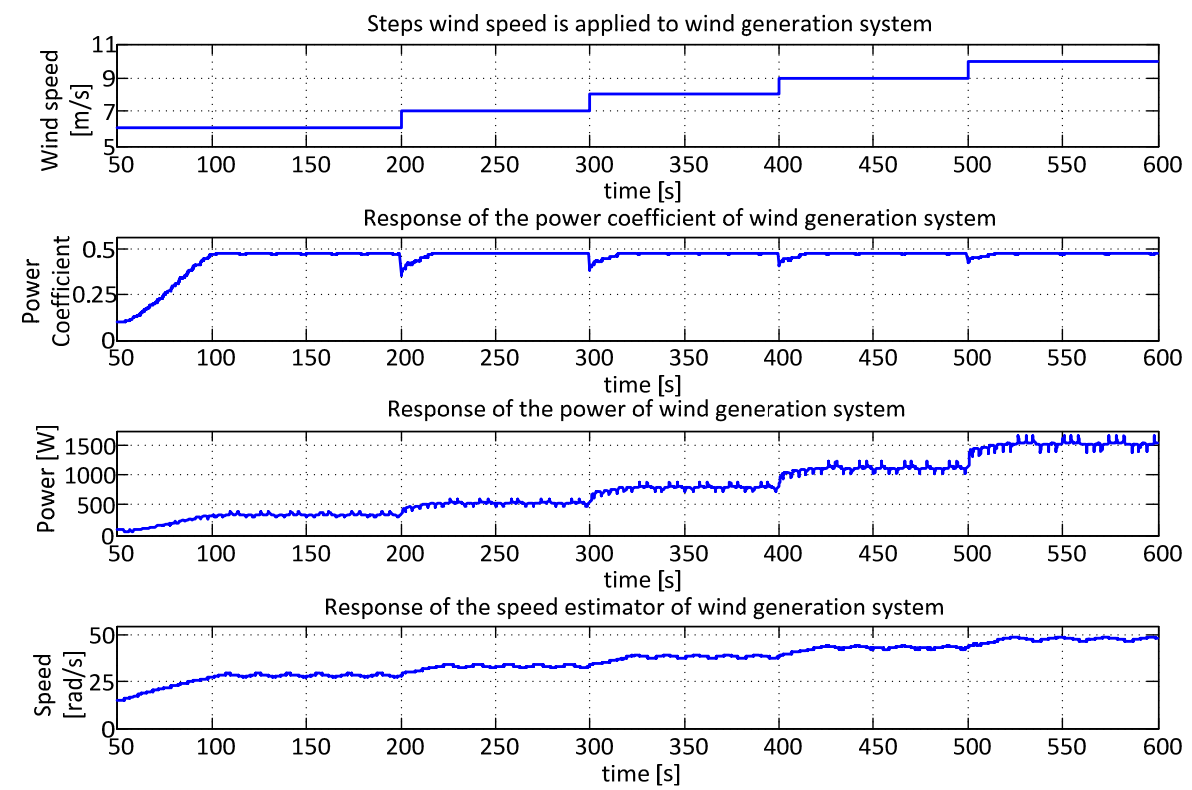

Fig. 10. Behavior of the WECS MPPT at a stepped variation of the wind speed. Top: Wind speed. Middle, up: Power coefficient. Middle, down: Generated power. Bottom: Estimated PMSG speed.

Fig. 11 depicts the performance of the $\mathrm{P} \& \mathrm{O}$ algorithm, at the same test conditions as Fig. 10, but representing the generated power vs. the PMSG speed, with the wind speed as a running parameter. Fig. 11 clearly demonstrates that the MPPT algorithm works to place the operation point close to the maximum available power for a given wind speed.

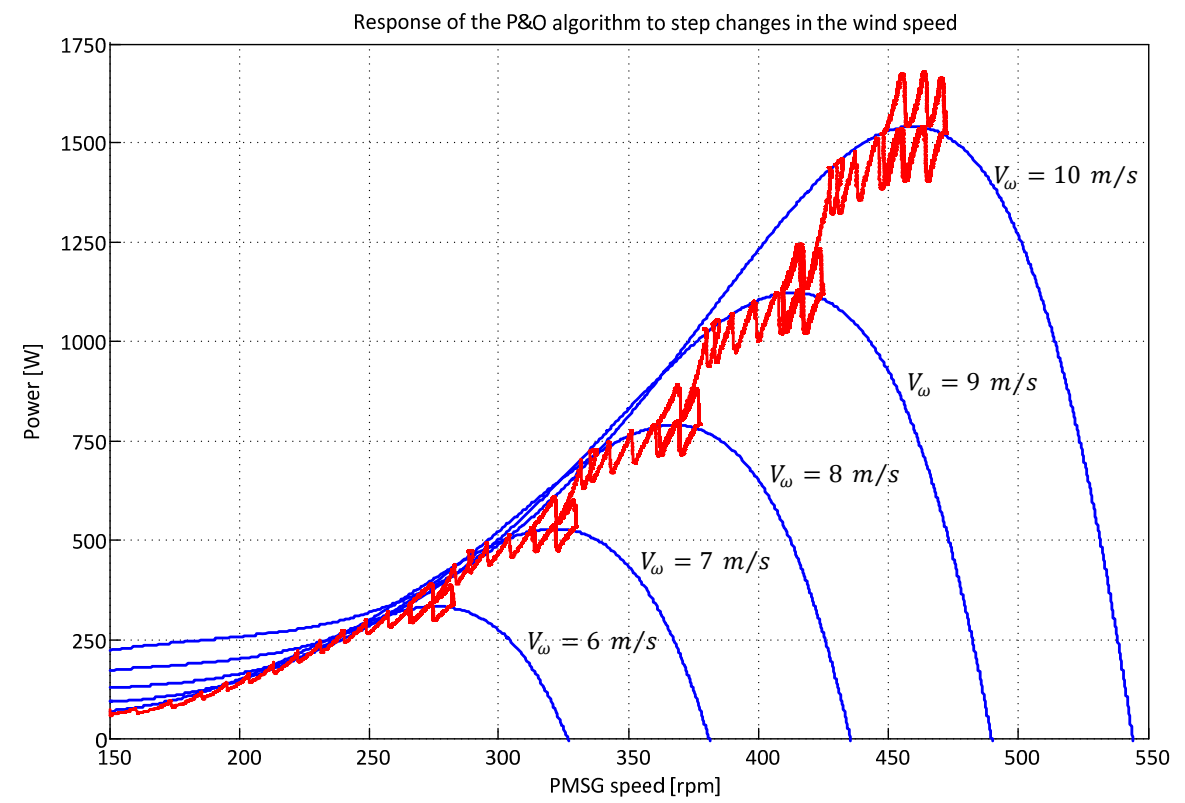

Fig. 11. Response of the $P \& O$ algorithm to step changes in the wind speed from $6 \mathrm{~m} / \mathrm{s}$ to $11 \mathrm{~m} / \mathrm{s}$.

Fig. 12 shows the current in one phase of the PMSG for several wind speed operation points. The proposed topology provides a THDi of the generator currents ranging from $7.8 \%$ to $11.1 \%$ and a PF ranging from 0.8 to 0.98 . 

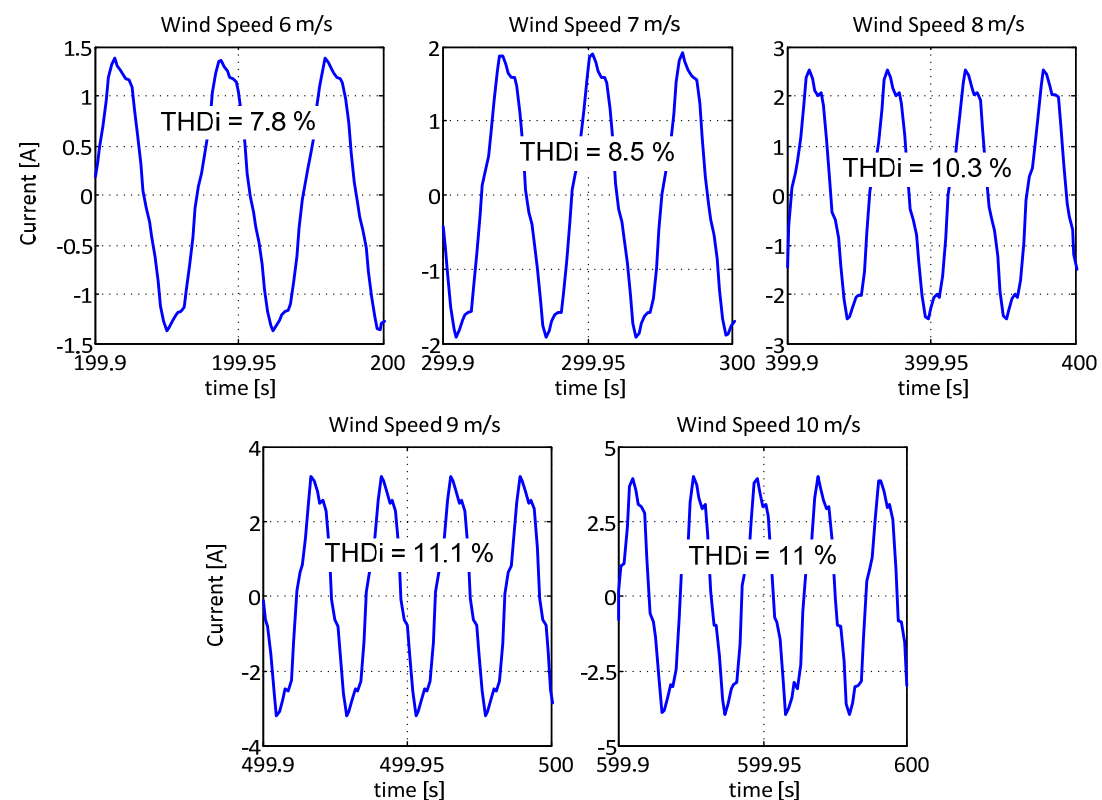

Fig. 12. Current in one phase of the PMSG controlled by a boost rectifier working in discontinuous conduction mode.

\section{EXPERIMENTAL RESULTS}

The three-phase DCM boost rectifier WECS has been implemented in an experimental prototype. The $2 \mathrm{~kW}$ PMSG is connected to a commercial AC motor drive Siemens Micromaster 440 that feeds a $5.5 \mathrm{~kW}$ induction motor 1LE1002CC322AA4Z from Siemens. This AC motor is connected to the PMSG. With the AC motor drive different wind speeds can be emulated by properly adjusting its speed reference.

The wind speed emulation, speed control loop, generator speed estimation and MPPT have been implemented by means of a DSP TMS320F28335. The PCC stage cannot be successfully implemented digitally inside the DSP because of practical issues. For a proper instantaneous overcurrent protection the required sampling frequency of the current through the power inductor should be at least 100 times the switching frequency, resulting in a sampling frequency of $1 \mathrm{MHz}$. This frequency would reduce the software execution time to 1 microsecond, a too small value for the DSP being used. Therefore, the PCC stage is implemented by means of a UC3823 PWM integrated circuit. Table I shows the most relevant values of the experimental WECS.

Some of the oscilloscope waveforms shown in the following are internal variables that are processed inside the DSP. Those variables are displayed by using the DSP PWM outputs and an analog a low pass filter with a cutoff frequency of $300 \mathrm{~Hz}$. This is a simple way to display some slow variables inside a DSP without the need of a digital to analog converter. The displayed internal DSP variables are: the estimated speed with a scale factor of $133.69 \mathrm{rpm} / \mathrm{V}$, the speed reference with scale factor of $133.69 \mathrm{rpm} / \mathrm{V}$, the power with a scale factor of $500 \mathrm{~W} / \mathrm{V}$, the electric torque with a scale factor of $14 \mathrm{Nm} / \mathrm{V}$, the power coefficient with a scale factor of $0.12 / \mathrm{V}$, and the wind speed with a scale factor of $2.4 \mathrm{~m} / \mathrm{s} / \mathrm{V}$.

Fig. 13 shows one phase-to-phase voltage at the PMSG output, $V_{a b}$, the PMSG output current in one phase, $i_{a}$, the current through one of the phase input inductances of the boost rectifier, $i_{L a}$, and the equivalent boost inductor DCM current, $i_{L}$. The generator speed is $460 \mathrm{rpm}$, the wind speed is $10 \mathrm{~m} / \mathrm{s}$, and the output power is $1.65 \mathrm{~kW}$. 


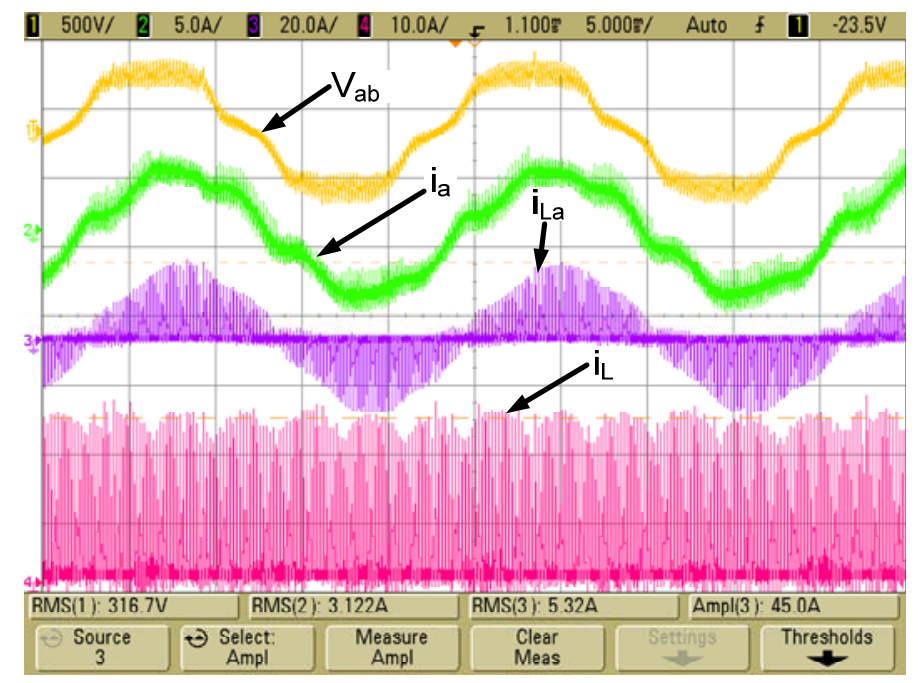

Fig. 13. Signals in the Boost Rectifier in DCM with input filter and PCC, at a generator speed of $460 \mathrm{rpm}$ and a wind speed of $10 \mathrm{~m} / \mathrm{s}$. Top: Phase to phase voltage at the output of the PMSG, $V_{a b}\left(500 \mathrm{~V} /\right.$ div). Middle, up: PMSG output current in one phase, $i_{a}(10 \mathrm{~A} / \mathrm{div})$. Middle, down: current through one of the phase input inductances of the boost rectifier, $i_{L a}(20 \mathrm{~A} / \mathrm{div})$. Bottom: equivalent boost inductor DCM current, $i_{L}(20 \mathrm{~A} / \mathrm{div})$. Time scale: $5 \mathrm{~ms} / \mathrm{div}$.

Fig. 14 depicts the behaviour of the generator speed estimator to steps of the actual speed in the whole operation range. It is observed that the experimental response is similar to the simulated response shown in Fig. 8. The LKF estimator has a a response time of $72 \mathrm{~ms}$.

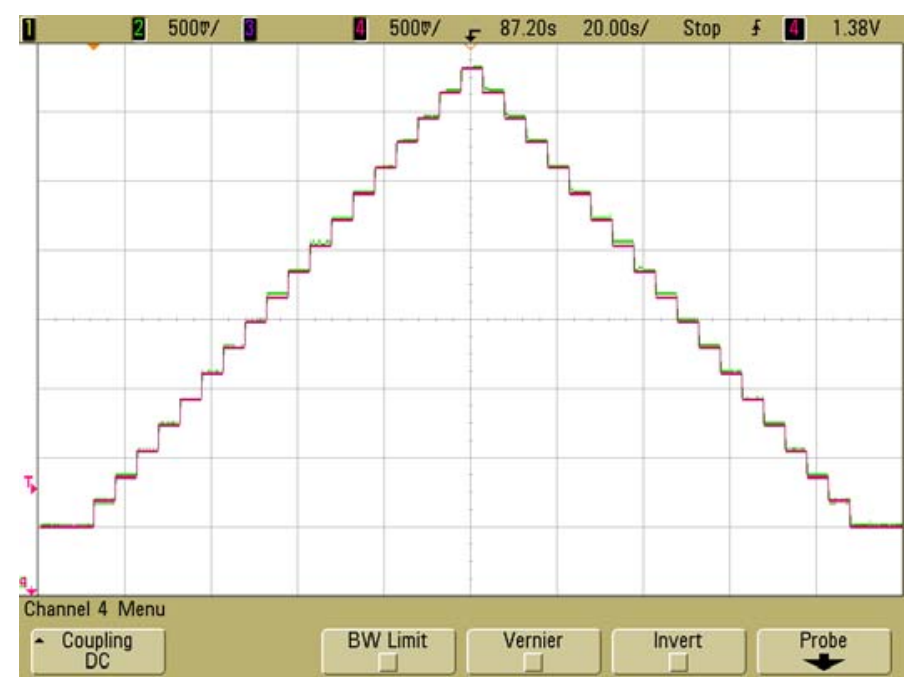

Fig. 14. The behavior of the speed estimators to speed steps. Red: PMSG speed (133,69 rpm/V, $500 \mathrm{mV} / \mathrm{div})$. Green: estimated speed by means of the LKF estimator $(133,69 \mathrm{rpm} / \mathrm{V}, 500 \mathrm{mV} / \mathrm{div})$. Time scale: $20 \mathrm{~s} / \mathrm{div}$.

Fig. 15 depicts the steady-state error of the estimated speed. The maximum transient deviation of this error is of $15.37 \mathrm{rpm}$, whereas the steady state error is $0.6685 \mathrm{rpm}$. 


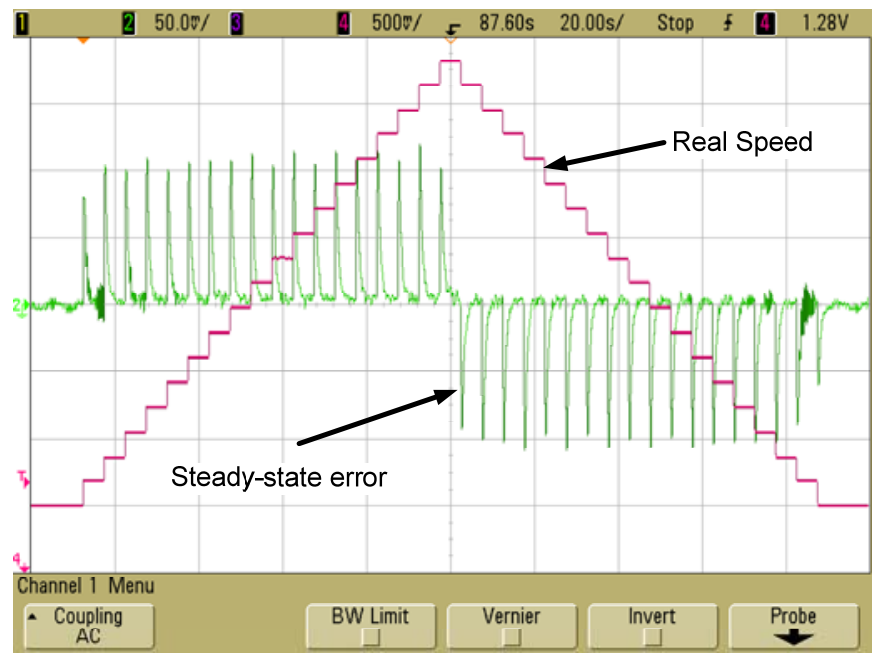

Fig. 15. Steady-state error of the speed estimators to speed steps. Real speed (133,69 rpm/V, $500 \mathrm{mV} / \mathrm{div})$. Time scale: $20 \mathrm{~s} / \mathrm{div}$.

Fig. 16 depicts the response of the speed loop to a stepped speed reference at a wind speed of $10 \mathrm{~m} / \mathrm{s}$. It is observed that the speed loop properly follows the speed reference. Fig 16 also shows the behavior of electric torque and the PMSG output power. A great agreement can be observed between these experimental results and the simulated ones in Fig. 9.

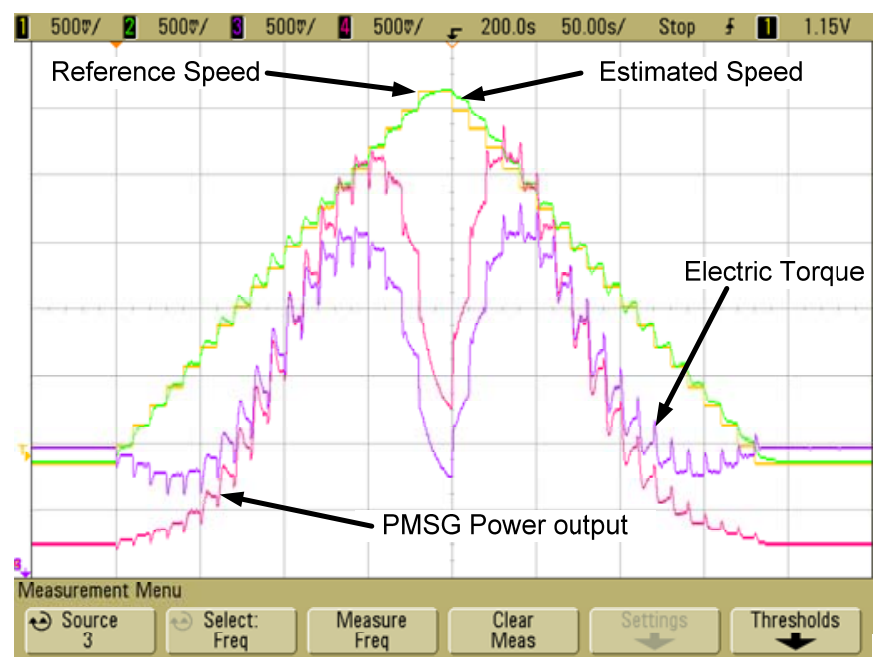

Fig. 16. Response of the speed loop to a stepped speed reference at a wind speed of $10 \mathrm{~m} / \mathrm{s}$. Reference speed $(133,69 \mathrm{rpm} / \mathrm{V}, 500 \mathrm{mV} / \mathrm{div})$. Estimated speed by means of the LKF estimator (133,69 rpm/V, $500 \mathrm{mV} / \mathrm{div})$. Electric Torque $(14 \mathrm{Nm} / \mathrm{V}, 500 \mathrm{mV} / \mathrm{div})$. PMSG Power output $(500 \mathrm{~W} / \mathrm{V}, 500 \mathrm{mV} / \mathrm{div})$. Time scale: $50 \mathrm{~s} / \mathrm{div}$.

Fig. 17 depicts the MPPT P\&O algorithm performance for a stepped variation of the wind speed, ranging from $6 \mathrm{~m} / \mathrm{s}$ to $10 \mathrm{~m} / \mathrm{s}$. It is shown the wind speed, the estimated speed, the PMSG power output and the power coefficient. It is observed that the MPPT succeeds in getting the maximum value of the power coefficient (0.47), so that the generated power is close to the maximum available power. The response of the LKF estimator is also shown. 


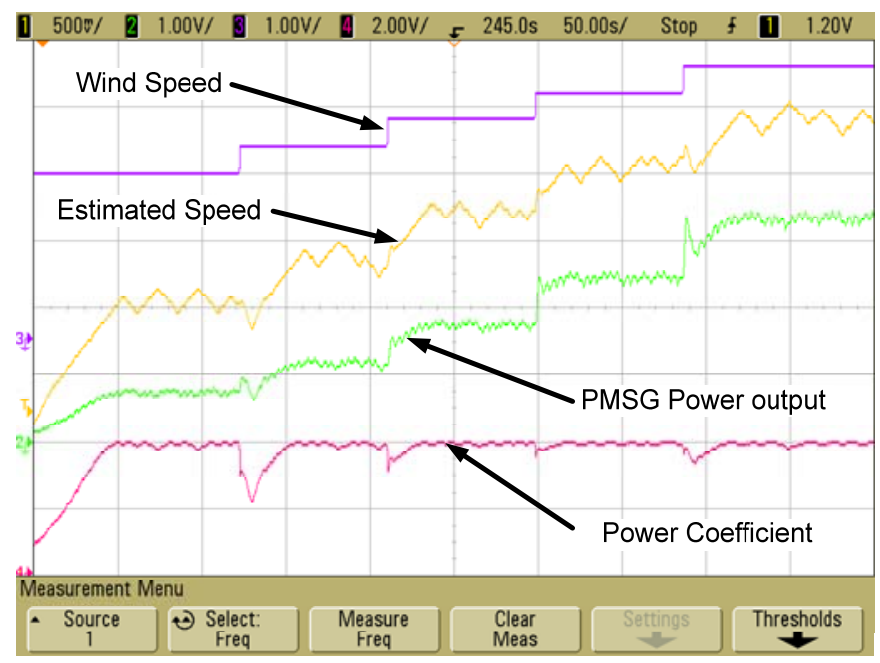

Fig. 17. Behavior of the WECS MPPT to steps in the wind speed. Wind speed $(2.4 \mathrm{~m} / \mathrm{s} / \mathrm{V}, 1 \mathrm{~V} /$ div). Estimated speed by means of the LKF estimator $(133,69$ $\mathrm{rpm} / \mathrm{V}, 500 \mathrm{mV} / \mathrm{div})$. PMSG Power output (500 W/V, $1 \mathrm{~V} / \mathrm{div})$. Power coefficient $(0.12 / \mathrm{V}, 2 \mathrm{~V} / \mathrm{div})$. Time scale: $50 \mathrm{~s} / \mathrm{div}$.

Fig. 18 shows the performance of the P\&O algorithm in the same test conditions of Fig. 17, but providing a Power vs. PMSG speed representation. This figure shows how the MPPT algorithm works to place the operation point close to the maximum available power for a given wind speed.

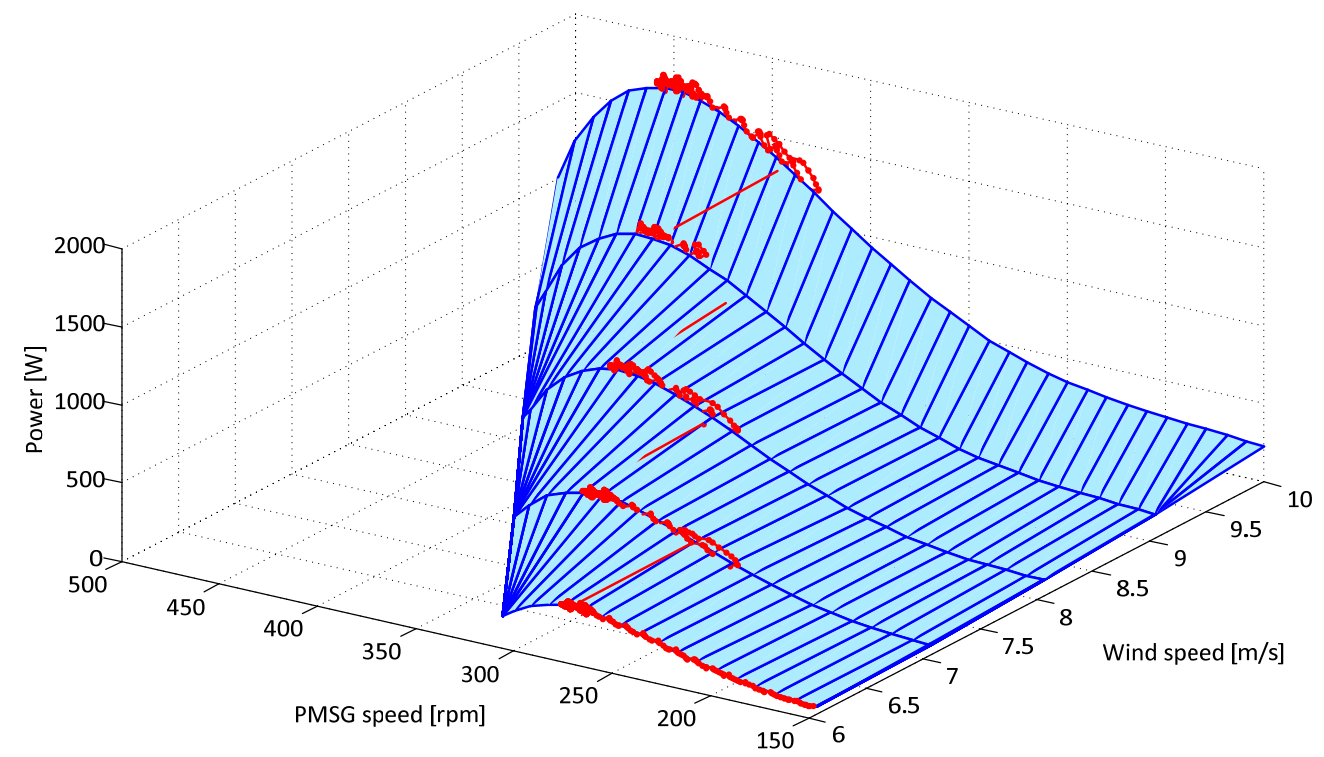

Fig. 18. Experimental response of the $P \& O$ algorithm to step changes in the wind speed from $6 \mathrm{~m} / \mathrm{s}$ to $10 \mathrm{~m} / \mathrm{s}$.

It can be concluded that Fig. 17 and Fig. 18 are in good agreement with their corresponding figures (10 and 11) showing the simulation results.

Fig. 19 shows the experimental values of the PMSG $\mathrm{THD}_{\mathrm{i}}$ at different operating points. The proposed topology provides an experimental $T H D_{i}$ ranging from $8 \%$ to $12 \%$ and a PF ranging from 0.9 to 0.98 [25]. 


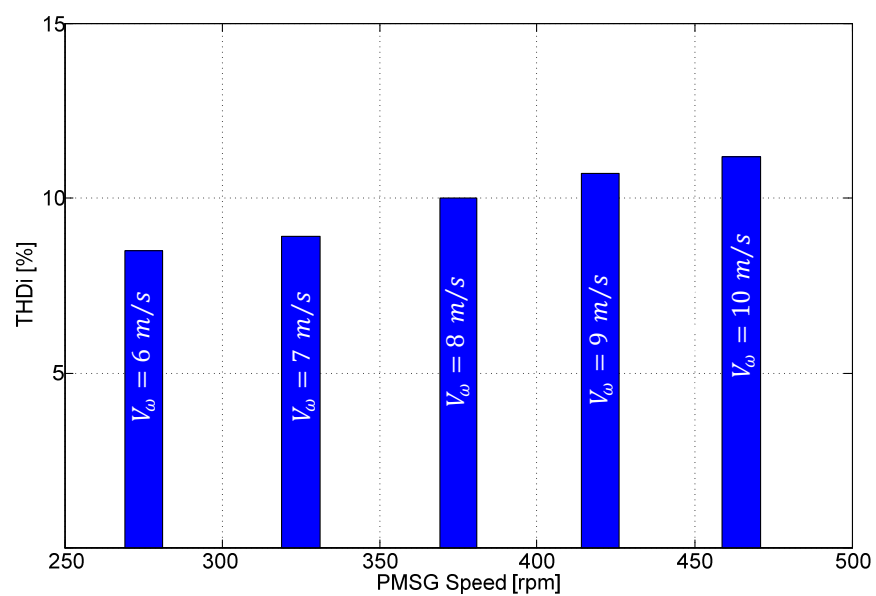

Fig. 19. Experimental values of the THDi at different operating points.

\section{CONCLUSION}

A low cost, high performance power converter for low power and variable speed WECS based on PMSG has been presented and evaluated in this paper. The obtained results show that the proposed system allows implementing efficient MPPT algorithms by cascade regulation of the rectifier current and the generator speed. The MPPT calculates the reference value for the speed control loop, which is closed without the need of mechanical sensors by using a speed estimator based on the Linear Kalman Filter. The speed controller calculates the reference for the current loop, which is directly related to the PMSG torque. The proposed WECS exhibits a low THD $_{\mathrm{i}}$ and a high PF with a simple DCM three-phase boost rectifier with input filter, working with PCC control. This topology has a smaller component count and is simpler than more complex topologies as back-to back converters, being a good option for low power WECS.

\section{REFERENCES}

[1] Thomas Ackermann, "Wind Power in Power Systems", England, Wiley, 2005.

[2] S. M. Muyeen, S. Shishido, Mohd Hasan Ali, R. Takahashi, T. Murata, J. Tamusa, " Application of Energy Capacitor System to Wind Power Generation", Wind Energy, vol. 11, pp. 335-350, 2008.

[3] J. Ladenbung, "Stated Public Preferences for On-land and Offshore Wind Power Generation-A Review", Wind Energy, vol. 12, pp. 171-181, 2009.

[4] T. Maeda, Y. Kamada, “ A review of wind energy activities in Japan”, Wind Energy, vol. 12, pp. 621-639, 2009.

[5] Jamal A. Baroudi, Venkata Dinavahi, Andrew M. Knight, "A review of power converter topologies for wind generators", Renewable Energy 32, pp. 2369-2385, 2007.

[6] Di Gerlando, G. Foglia, M. Iacchetti, R. Perini, "Analysis and Test of Diode Rectifiers Solutions in Grid Connected Wind Energy Conversion Systems Employing Modular Permanent Magnet Synchronous Generators", IEEE Transactions on Industrial Electronics, In Press, 10.1109/TIE.2011.2157295.

[7] Y. Jang, M. M. Jovanovic, "A New Input-Voltage Feedforward Harmonic-Injection Technique Nonlinear Gain Control for Single-Switch, Three-Phase, DCM Boost Rectifiers" IEEE Trans. on Power Electronics, vol. 20, no. 1, pp. 268-277, March 2000.

[8] H. Athab, D. Lu, K. Ramar, "A Single-Switch AC/DC Flyback Converter Using A CCM/DCM Quasi-Active Power Factor Correction Front-End", IEEE Transactions on Industrial Electronics, In Press, 10.1109/TIE.2011.2158771.

[9] P. Barbosa, F. Canales, J. C. Crebier, F.C. Lee, "Interleaved Three-Phase Boost Rectifiers Operated in the Discontinuous Conduction Mode: Analysis, Design Considerations and Experimentation" IEEE Trans. on Power Electronics, vol. 16, no. 5, pp. 724-734, Sep. 2001.

[10] Y. Kai, R. Xinbo, M. Xiaojing, Y. Zhihong, "Variable-Duty-Cycle Control to Achieve High Input Power Factor for DCM Boost PFC Converter", IEEE Transactions on Industrial Electronics, Vol. 58 (5), pp. 1856 - 1865, 2011.

[11] M. Andriollo, M. De Bortoli, G. Martinelli, A. Morini and A. Tortella, "Control Strategy of a Wind Turbine Drive by an Integrated Model", Wind Energy, vol. 12, pp. 33-49, 2009.

[12] Anca D. Hansen, Gabriele Michalke, "Modelling and Control of Variablespeed Multi-pole Permanent Magnet Synchronous Generator Wind Turbine", Wind Energy, vol. 11, pp. 537-554, 2008.

[13] N. Salvatore, A. Caponio, F. Neri, S. Stasi, G.L. Cascella, "Optimization of Delayed-State Kalman-Filter-Based Algorithm via Differential Evolution for Sensorless Control of Induction Motors", IEEE Transactions on Industrial Electronics, Vol. 57 (1), pp. 385-394, 2010.

[14] S.M.R. Kazmi, H. Goto, Hai-Jiao Guo; O. Ichinokura, "A Novel Algorithm for Fast and Efficient Speed-Sensorless Maximum Power Point Tracking in Wind Energy Conversion Systems", IEEE Transactions on Industrial Electronics, Vol. 58(1), pp. 29-36, 2011.

[15] M. Pucci, M. Cirrincione, "Neural MPPT Control of Wind Generators With Induction Machines Without Speed Sensors", IEEE Transactions on Industrial Electronics, Vol. 58 (1), pp. 37-47, 2011.

[16] O. Carranza, E. Figueres, G. Garcerá, R. Ortega, D. Velasco, "Low Power Wind Generation System based on Variable Speed Permanent Magnet Synchronous Generators" in Proc. IEEE ISIE, 2011, pp. 1063-1068.

[17] Yin Ming, Li Gengyin, Zhou Ming, Zhao Chengyong, "Modeling of the Wind Turbine with a Permanent Magnet Synchronous Generator for Integration", IEEE Power Engineering Society General Meeting, 2007, $24-28$ June 2007 pp. 1-6.

[18] O. Carranza, E. Figueres, G. Garcera, L. G. Gonzalez, F. Gonzalez-Espin, "Peak Current Mode Control of a Boost Rectifier with Low Distortion of the Input Current for Wind Power Systems based on Permanent Magnet Synchronous Generators", 13th European Conference on Power Electronics and Applications, EPE '09. 8-10 Sept. 2009 pp. 1-10.

[19] Ali M. Eltamaly, "Harmonics reduction of three-phase boost rectifier by modulating duty ratio", Electric Power Systems Research 77, pp. 1425-1431, 2007.

[20] V. Vorperian, "Simplified analysis of PWM converters using model of PWM switch I and II" IEEE Trans. on Aerospace and Electronic Systems, vol. 26, no. 3, pp. 490-505, may 1990. 
[21] R. B. Ridley, "A new, continuous-time model for current-mode control (power convertors)", IEEE Trans. on Power Electronics, vol. 6, no. 2, pp. 271280, April 1991.

[22] O. Carranza, E. Figueres, G. Garcera, C. L. Trujillo, D. Velasco, "Comparison of Speed Estimators Applied to Wind Generation Systems with Noisy Measurement Signals", ISIE 2010 IEEE International Symposium on Industrial, 4-7 July 2010, pp. 3317-3322.

[23] Yaoqin J, Zhongqing Y, Binggang C. "A new maximum power point tracking control scheme for wind generation." International conference on power system technology, PowerCon 2002 IEEE-PES/CSEE, Kunming, China; October 13-17 2002.

[24] PSIM 7.0 User's Guide (2006), Powersim Inc., March 2006.

[25] Carranza O, Garcerá G, Figueres E, González LG. "Peak current mode control of three-phase boost rectifiers in discontinuous conduction mode for small wind power generators". Applied Energy, Vol. 87(8):pp. 2728-36, 2010. 